\title{
Implementasi Algoritma K-Means dalam Pengklasteran untuk Rekomendasi Penerima Beasiswa PPA di UDINUS
}

\author{
Abu Salam ${ }^{1}$, Diyan Adiatma ${ }^{2}$, Junta Zeniarja ${ }^{3}$ \\ Fakultas Ilmu Komputer, Universitas Dian Nuswantoro, \\ Jl. Nakula I No 5 - 7 Semarang, 50131, Telp (024)3515261 \\ E-mail: ${ }^{1}$ abu.salam@dsn.dinus.ac.id, ${ }^{2} 111201408045 @$ mhs.dinus.ac.id, ${ }^{3}$ junta@dsn.dinus.ac.id
}

Diterima: 11 Februari 2020; Direvisi: 22 April 2020; Disetujui: 6 Mei 2020

\begin{abstract}
Abstrak
Rekomendasi penerima beasiswa Peningkatan Prestasi Akademik (PPA) dikelompokkan menjadi 2 cluster yaitu diterima dan tidak diterima untuk mendapatkan beasiswa. Algoritma K-Means merupakan teknik unsupervised learning yang dapat digunakan dalam mengelompokkan data pengajuan beasiswa. Tujuan dari penelitian ini adalah untuk merekomendasikan penerima beasiswa dengan menggunakan algoritma k-means, hasil rekomendasi berupa penempatan data pendaftar beasiswa ke masing-masing kelompok cluster yang dihasilkan. Eksperimen proses clustering dilakukan menggunakan data pendaftar beasiswa PPA dari biro kemahasiswaan udinus tahun 2016 sebanyak 44 pendaftar beasiswa PPA. Melalui seleksi atribut, $k$-means ini melakukan perhitungan untuk menempatkan setiap data ke cluster yang sudah ditentukan. Sebanyak 154 mahasiswa direkomendasikan mendapatkan beasiswa PPA sedangkan 287 mahasiswa tidak mendapatkan.
\end{abstract}

Kata Kunci: data mining, beasiswa ppa, clustering, $k$-means, rekomendasi

\begin{abstract}
Recommendations for recipients of Peningkatan Prestasi Akademik (PPA) scholarships are grouped into 2 clusters, namely accepted and not accepted for scholarships. The K-Means algorithm is an algorithm of clustering techniques that can group scholarship recipient data. The purpose of this study is to recommend scholarship recipients using the k-means algorithm, the results of this recommendation are seen from the placement of members to each cluster produced. The data used in this study is the 2016 PPA scholarship registrant data in students bureau Udinus with the number of 441 datasets. Through attribute selection, this $k$-means performs calculations to place each data into the specified cluster. Total of 154 students were recommended to get PPA scholarships while 287 students did not get.
\end{abstract}

Keywords: data mining, ppa scholarship, clustering, $k$-means, recommendation

\section{PENDAHULUAN}

Setiap warga Negara berhak mendapatkan kemudahan dalam pelayanan pendidikan yang layak dan bermutu bagi setiap warga negaranya seperti tercantum pada Pasal 31 UUD 1945 [1]. Mewajibkan warga negaranya untuk mengenyam pendidikan setinggi-tingginya. Pemerintah telah berusaha menekan angka putus kuliah bagi mahasiswa yang memiliki prestasi tinggi namun mengalami kesulitan dalam perekonomian [2].

Universitas Dian Nuswantoro sebagai salah satu universitas besar di Indonesia memiliki 20 jenis beasiswa yang ditawarkan kepada semua mahasiswa dari pemerintah maupun non- 
pemerintah melalui Biro Mahasiswa (Bima). Beasiswa Peningkatan Prestasi Akademik (PPA) adalah salah satu beasiswa yang menjadi hak bagi mahasiswa UDINUS. PPA ditawarkan kepada mahasiswa kurang berprestasi, baik akademik maupun non-akademik. Penyelenggara beasiswa PPA adalah Kopertis Wilayah VI dengan persyaratan antara lain fotocopy kartu mahasiswa, ktp dengan umur maksimal 23 tahun, foto ukuran $3 \times 4$ dua lembar dengan memakai jas almamater, nilai IPK, minimal semester 1 maksimal semester 6 untuk S1, fotocopy rekening buku tabungan, fotocopy kartu keluarga dan fotocopy krs terbaru dengan legalisir fakultas.

Pada tahun 2016, tercatat jumlah mahasiswa udinus pendaftar beasiswa PPA sebanyak 441 mahasiswa dari fakultas dan angkatan yang berbeda-beda. Berdasarkan pada kriteria penerimaan beasiswa PPA, terdapat bermacam-macam kriteria yang harus dipenuhi oleh mahasiswa untuk mendapatkan beasiswa tersebut. Permasalahan yang terjadi dalam melakukan seleksi penerimaan beasiswa PPA di udinus adalah sulitnya mengelola data dan atribut dalam jumlah banyak untuk menentukan penerima beasiswa PPA sehingga mengakibatkan beasiswa tersebut tidak tepat sasaran. Maksud dari tidak tepat sasarannya disini adalah mahasiswa yang seharusnya layak mendapatkan beasiswa malah tidak mendapatkannya, justru mahasiswa yang tidak layak malah mendapatkan beasiswa tersebut. Tentunya Udinus juga menginginkan agar proses seleksi beasiswa PPA dapat berjalan dengan semestinya.

Salah satu penelitian oleh Nurul Rohmawati [3] dengan menggunakan algoritma KMeans, peneliti menggunakan Rapidminer Studio 5 untuk melakukan pemodelan pengelompokan penerima beasiswa. Berdasarkan 36 data mahasiswa yang terdaftar, peneliti melibatkan atributatribut yang dia pilih untuk masuk ke tahap pemodelan yaitu NPM, IPK, jumlah SKS, penghasilan dan jumlah tanggungan orang tua. Hasil yang diperoleh ketika mengeksekusi data tersebut dengan algoritma K-Means bahwa cluster mendapatkan hasil sebesar 0.750 atau $75 \%$. Hasil ini membuat bahwa algoritma K-Means memiliki hasil cluster yang baik dalam kasus beasiswa pada tingkat universitas.

Pada penelitian yang dilakukan oleh Fiqih Satria [4] peneliti melakukan perbandingan Ward dan K-Means untuk proses penentuan cluster data pemohon beasiswa PPA dan BBA. Proses clustering pada beasiswa PPA, algoritma K-Means dan Ward sama-sama memiliki nilai rasio yang sama yaitu sebesar 0,749959584\% sedangkan pada beasiswa BBA, metode Ward memiliki rasio yang lebih baik daripada K-Means yaitu sebesar 0,5346668\% sedangkan K-Means mendapatkan 0,831525302\%. Hasil ini telah menetapkan bahwa Algoritma K-Means dinilai baik dalam menyelesaikan kasus beasiswa PPA sedangkan Ward dinilai baik dalam penyelesaian kasus beasiswa BBA dalam penelitian ini.

Dari latar belakang tersebut akan dilakukan penelitian tentang peran data mining dalam menyelesaikan permasalahan untuk proses seleksi penerima beasiswa PPA di udinus. Teknik data mining clustering dengan algoritma K-Means akan diterapkan pada penelitian ini untuk memecahkan masalah tersebut serta menghasilkan sebuah rekomendasi kelompok penerima beasiswa PPA.

\section{METODE PENELITIAN}

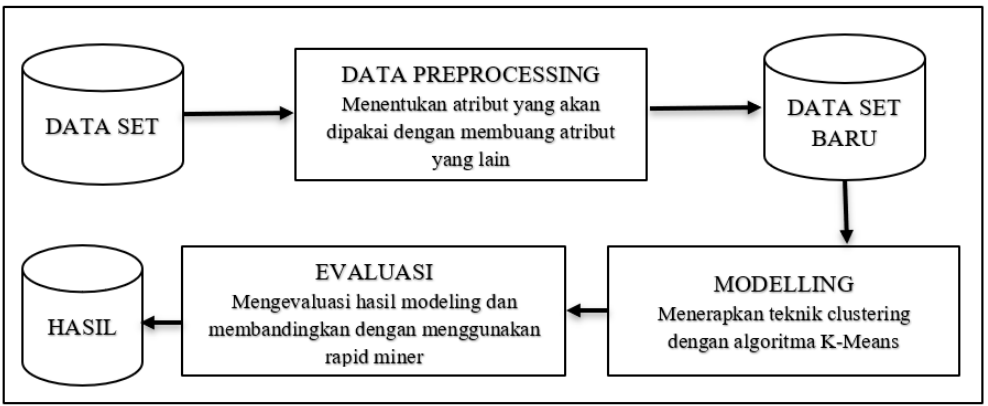

Gambar 1. Metode Penelitian 
Tahapan-tahapan yang dilakukan untuk rekomendasi terhadap data pendaftar beasiswa PPA diperlukan sebuah proses untuk mengolah data tersebut menjadi sebuah hasil rekomendasi penerima beasiswa seperti pada gambar 1 .

\subsection{Dataset}

Dataset yang digunakan adalah data dari biro mahasiswa udinus yaitu data pendaftar beasiswa ppa tahun 2016 dengan jumlah 441 dataset yang tertera pada gambar 2, dataset ini pada saat penelitian sudah dalam tahap evaluasi untuk peserta penerima beasiswa PPA, dari hasil yang nanti diperoleh bisa sebagai data referensi pembanding untuk proses evaluasi.

\begin{tabular}{|c|c|c|c|c|c|c|c|c|c|c|c|c|}
\hline & A & B & c & D & E & $\mathrm{F}$ & G & H & I & J & $\mathrm{k}$ & L \\
\hline 1 & No & NIM & Nama Pendaftar & IPK & \begin{tabular}{|l} 
Penghasilan Real (Rp) \\
\end{tabular} & Tanggungan Real & Domisili Real & Semester Real & Aktivis Real & PKM & No Rekening & \\
\hline 2 & 1 & A11.2013.07397 & ALMAS SHIDQI GAMARAMADHANI & 3.55 & 1.000 .000 & 2 & 2 & 6 & 0 & 0 & $2-099-13835-4$ & \\
\hline 3 & 2 & A11.2013.07427 & ANTONIUS ERICK HANDOYO & 3.13 & 4.000 .000 & 4 & 2 & 5 & 2 & 0 & $3-088-04229-7$ & \\
\hline 4 & 3 & A11.2013.07429 & ADLI AZHAR ARRASYID & 3.35 & 2.000 .000 & 4 & 2 & 5 & 3 & 10 & 2-099-13271-2 & \\
\hline 5 & 4 & A11.2013.07432 & RANDY ARI PRATAMA & 3.4 & 1.200 .000 & 1 & 2 & 5 & 3 & 10 & 2-099-17338-9 & \\
\hline 6 & 5 & A11.2013.07433 & DANI PRAMASITHA & 3.45 & 1.500 .000 & 1 & 2 & 5 & 2 & 0 & 2-034-19024-3 & \\
\hline 7 & 6 & A11.2013.07455 & TEGUH SUNNARTO & 3.68 & 1.000 .000 & 4 & 2 & 5 & 0 & 0 & 2-099-13255-1 & \\
\hline 8 & 7 & A11.2013.07456 & AGUS PRASETYO & 3.13 & 1.325 .000 & 4 & 2 & 6 & 3 & 10 & 2-099-13798-6 & \\
\hline 9 & 8 & A11.2013.07459 & ELLEN TOMY SASMITA & 3.39 & 1.500 .000 & 2 & 2 & 5 & 0 & 0 & $2-099-17337-1$ & \\
\hline 10 & 9 & A11.2013.07462 & WIBOWO & 3.17 & 1.800 .000 & 2 & 1 & 6 & 2 & 10 & $2-099-13239-9$ & \\
\hline 11 & 10 & A11.2013.07468 & TIAZ ISKANDAR MUDA & 3.74 & 4.368 .000 & 3 & 2 & 5 & 2 & 10 & 2-099-13196-1 & \\
\hline 12 & 11 & A11.2013.07504 & MUHAMAD FARIKHIN & 3.67 & 1.500 .000 & 4 & 2 & 5 & 0 & 0 & 2-099-13448-1 & \\
\hline 13 & 12 & A11.2013.07552 & AMIN ROSYID KARIM & 3.13 & 3.713 .000 & 2 & 2 & 6 & 0 & 0 & $2-099-13805-2$ & \\
\hline 14 & 13 & A11.2013.07582 & FIRMAN SYAHRIZAL & 3.33 & 4.500 .000 & 2 & 2 & 5 & 0 & 0 & 2-099-13225-9 & \\
\hline 15 & 14 & A11.2013.07590 & Yanuar Pambudi & 3.26 & 3.000 .000 & 2 & 2 & 6 & 0 & 0 & $2-099-13226-7$ & \\
\hline 16 & 15 & A11.2013.07615 & KAMAL AZIZ ADINATA & 3.81 & 1.650 .000 & 2 & 2 & 6 & 0 & 10 & 2-099-13032-9 & \\
\hline 17 & 16 & A11.2013.07618 & DICKY WAHYU SETIAWAN & 3.33 & 2.100 .000 & 3 & 2 & 5 & 0 & 0 & $2-099-13439-1$ & \\
\hline 18 & 17 & A11.2013.07685 & FAUZI ARYANTO & 3.44 & 1.500 .000 & 1 & 2 & 6 & 2 & 0 & 2-099-12953-3 & \\
\hline 19 & 18 & A11.2013.07689 & PUNGKY SEPTIANA TIRAJANI & 3.53 & 1.500 .000 & 3 & 2 & 5 & 0 & 10 & 2-099-12974-6 & \\
\hline 20 & 19 & A11.2013.07736 & FITRIA KINTA NURRIZKI & 3.35 & 1.000 .000 & 1 & 2 & 6 & 2 & 10 & 2-099-13144-9 & \\
\hline 21 & 20 & A11.2013.07747 & ALFREDO OCTAVIAN & 3.44 & 3.000 .000 & 3 & 2 & 6 & 2 & 0 & $2-099-13178-3$ & \\
\hline 22 & 21 & A11.2013.07808 & Fatma Eranisa & 3.52 & 1.061 .300 & 3 & 2 & 6 & 2 & 10 & 2-099-14113-4 & \\
\hline 23 & 22 & A11.2013.07816 & ADERINA BAGAS ASTUTI & 3.38 & 4.555.400 & 3 & 2 & 5 & 0 & 0 & 2-099-14121-5 & \\
\hline ( & , & \multicolumn{2}{|c|}{ PeningkatanPrestasiAkademik(PPA } & & & & 1 & & & & & \\
\hline
\end{tabular}

Gambar 2. Data Pendaftar Beasiswa PPA Tahun 2016

\subsection{Pre-Processing}

Pada gambar 4 menampilkan tahap preprocesing dilakukan pemilahan atribut yang tidak dipakai dalam penelitian ini, dari 10 atribut yang tidak dipakai berjumlah 3 yaitu nim, nama dan nomor rekening, karena merupakan atribut yang sifatnya menjelaskan entitas data mahasiswa saja, dianggap tidak memiliki pengaruh untuk proses seleksi beasiswa.

\begin{tabular}{|c|c|c|c|c|c|c|c|c|c|c|c|c|}
\hline 4 & A & B & s. & D & E & $\mathrm{F}$ & G & H & 1 & j & $k$ & $L$ \\
\hline 1 L & No & NIM & Nama Pendaftar & IPK & Penghasilan Real (Rp) & Tanggungan Real & Domisili Real & Semester Real & Aktivis Real & PKM & No Rekening & \\
\hline 2 & 1 & A11.2013.07397 & ALMAS SHIDQI GAMARAMADHANI & 3.55 & 1.000 .000 & 2 & 2 & 6 & 0 & 0 & 2-099-13835-4 & \\
\hline 3 & 2 & A11.2013.07427 & ANTONIUS ERICK HANDOYO & 3.13 & 4.000 .000 & 4 & 2 & 5 & 2 & 0 & 3-088-04229-7 & \\
\hline 4 & 3 & A11.2013.07429 & ADLI AZHAR ARRASYID & 3.35 & 2.000 .000 & 4 & 2 & 5 & 3 & 10 & 2-099-13271-2 & \\
\hline 5 & 4 & A11.2013.07432 & RANDY ARI PRATAMA & 3.4 & 1.200 .000 & 1 & 2 & 5 & 3 & 10 & 2-099-17338-9 & \\
\hline 6 & 5 & A11.2013.07433 & DANI PRAMASITHA & 3.45 & 1.500 .000 & 1 & 2 & 5 & 2 & 0 & $2-034-19024-3$ & \\
\hline 7 & 6 & A11.2013.07455 & TEGUH SUNNARTO & 3.68 & 1.000 .000 & 4 & 2 & 5 & 0 & 0 & 2-099-13255-1 & \\
\hline 8 & 7 & A11.2013.07456 & AGUS PRASETYO & 3.13 & 1.325 .000 & 4 & 2 & 6 & 3 & 10 & 2-099-13798-6 & \\
\hline 9 & 8 & A11.2013.07459 & ELLEN TOMY SASMITA & 3.39 & 1.500 .000 & 2 & 2 & 5 & 0 & 0 & 2-099-17337-1 & \\
\hline 10 & 9 & A11.2013.07462 & WIBOWO & 3.17 & 1.800 .000 & 2 & 1 & 6 & 2 & 10 & 2-099-13239-9 & \\
\hline 11 & 10 & A11.2013.07468 & TIAZ ISKANDAR MUDA & 3.74 & 4.368 .000 & 3 & 2 & 5 & 2 & 10 & 2-099-13196-1 & \\
\hline 12 & 11 & A11.2013.07504 & MUHAMAD FARIKHIN & 3.67 & 1.500 .000 & 4 & 2 & 5 & 0 & 0 & 2-099-13448-1 & \\
\hline 13 & 12 & A11.2013.07552 & AMIN ROSYID KARIM & 3.13 & 3.713 .000 & 2 & 2 & 6 & 0 & 0 & 2-099-13805-2 & \\
\hline 14 & 13 & A11.2013.07582 & FIRMAN SYAHRIZAL & 3.33 & 4.500 .000 & 2 & 2 & 5 & 0 & 0 & 2-099-13225-9 & \\
\hline 15 & 14 & A11.2013.07590 & Yanuar Pambudi & 3.26 & 3.000 .000 & 2 & 2 & 6 & 0 & 0 & 2-099-13226-7 & \\
\hline 16 & 15 & A11.2013.07615 & KAMAL AZIZ ADINATA & 3.81 & 1.650 .000 & 2 & 2 & 6 & 0 & 10 & 2-099-13032-9 & \\
\hline 17 & 16 & A11.2013.07618 & DICKY WAHYU SETIAWAN & 3.33 & 2.100 .000 & 3 & 2 & 5 & 0 & 0 & 2-099-13439-1 & \\
\hline 18 & 17 & A11.2013.07685 & FAUZI ARYANTO & 3.44 & 1.500 .000 & 1 & 2 & 6 & 2 & 0 & 2-099-12953-3 & \\
\hline 19 & 18 & A11.2013.07689 & PUNGKY SEPTIANA TIRAJANI & 3.53 & 1.500 .000 & 3 & 2 & 5 & 0 & 10 & 2-099-12974-6 & \\
\hline 20 & 19 & A11.2013.07736 & FITRIA KINTA NURRIZKI & 3.35 & 1.000 .000 & 1 & 2 & 6 & 2 & 10 & 2-099-13144-9 & \\
\hline 21 & 20 & A11.2013.07747 & ALFREDO OCTAVIAN & 3.44 & 3.000 .000 & 3 & 2 & 6 & 2 & 0 & 2-099-13178-3 & \\
\hline 22 & 21 & A11.2013.07808 & Fatma Eranisa & 3.52 & 1.061 .300 & 3 & 2 & 6 & 2 & 10 & 2-099-14113-4 & \\
\hline 23 & 22 & $\Delta 11201207816$ & ADERINA BAGAS ASTUTI & 3.38 & 4.555.400 & 3 & 2 & 5 & 0 & 0 & 2-099-14121-5 & \\
\hline 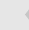 & 1 & PeningkatanP & estasiAkademik(PPA & & & & 1 & & & & & \\
\hline
\end{tabular}

Gambar 3. Preprocesing 


\subsection{K-Means}

Merupakan algoritma pada unsupervised learning pada proses clustering yang mengelompokan data berdasarkan kemiripan / kesamaan. Data dengan karakter sama akan dikelompokkan pada satu cluster sedangkan data dengan karakter berbeda akan dikelompokkan pada cluster yang lain [5]. Menurut Nurul Rohmawati, telah berhasil menjelaskan secara detail bagaimana cara kerja algoritma K-Means sebagai berikut [3]:

1. Menentukan jumlah kelompok cluster (Nilai K).

2. Menentukan titik pusat cluster (Centroid) sebanyak jumlah $\mathrm{k}$ yang sudah ditentukan.

3. Menghitung jarak centroid dengan keseluruhan data yang ada dengan rumus kesamaan, dalam penelitian ini digunakan Euclidean pada persamaan (1). Berikut adalah rumus Euclidean Distance:

$$
d(x, y)=\sqrt{\sum_{i=1}^{n}(x i-y i)^{2}}
$$

Keterangan: $\mathrm{x}=$ data $\mathrm{x} ; \mathrm{y}=$ data $\mathrm{y} ; \mathrm{n}=$ jumlah (atribut); $\mathrm{d}(\mathrm{x}, \mathrm{y})=$ jarak antara data $\mathrm{x}$ dan y.

4. Melakukan langkah 2 sampai langkah 4 hingga anggota setiap cluster tidak mengalami perubahan.

5. Jika sudah tidak ada nilai yang berubah, maka iterasi terakhir digunakan untuk parameter dimana sebagai acuan menentukan prosentase data [3].

\subsection{Centroid}

Algoritma K-Means menggunakan model centroid untuk membentuk cluster. Centroid adalah titik pusat cluster yang berupa sebuah nilai yang digunakan sebagai pusat untuk menghitung nilai kesamaan data. Penentuan centroid awal (initial centroid) dapat dilakukan dengan pengambilan data dari sumber secara acak sesuai jumlah $\mathrm{K}$ yang sudah ditentukan [6].

Proses perbaruan centroid untuk iterasi berikutnya dapat diperoleh dari hasil rata-rata cluster dengan menggunakan rumus seperti pada persamaan (2) [3].

Keterangan:

$$
\mu j(t+1)=\frac{1}{N s j} \sum_{j \in S j} x j
$$

$$
\begin{array}{ll}
\mu j(t+1) & =\text { centroid iterasi } \mathrm{ke}(t+1) \\
\mathrm{N} s j & =\text { jumlah data cluster } S j
\end{array}
$$

\section{HASIL DAN PEMBAHASAN}

Penelitian implementasi perhitungan algoritma K-Means dilakukan dengan menggunakan tools Rapid Miner Studio. Rapid Miner sebagai tools dapat memudahkan usernya untuk melakukan perhitungan menggunakan operator. Operator berfungsi untuk memodifikasi data dan kemudian dihubungkan dengan node-node operator [7]. User menghubungkan nodenode tersebut untuk melihat hasilnya berupa tampilan grafik. Rapid Miner pada gambar 1 digunakan untuk melakukan proses ekstraksi data menggunakan metode yang ada pada data mining [8].

Dari proses penelitian yang dilakukan didapatkan hasil dari 441 dataset pendaftar Beasiswa PPA tahun 2016 seperti pada gambar 5 dan gambar 6, terdapat 154 data mengikuti cluster 0 yang artinya direkomendasikan diterima atau mendapatan beasiswa sedangkan 287 data lainnya mengikuti cluster 1 yang artinya tidak direkomendasikan atau tidak mendapatkan beasiswa. 


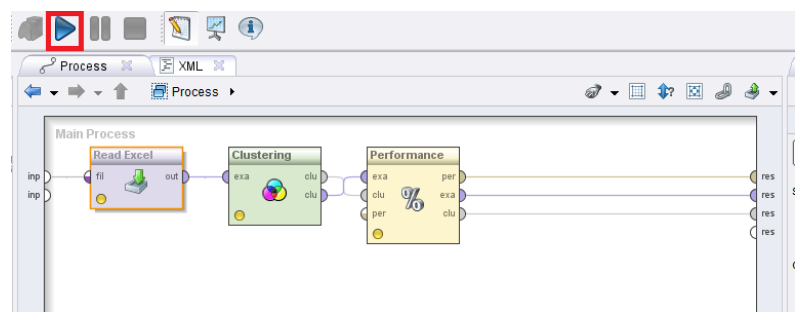

Gambar 4. Konfigurasi Rapid Miner

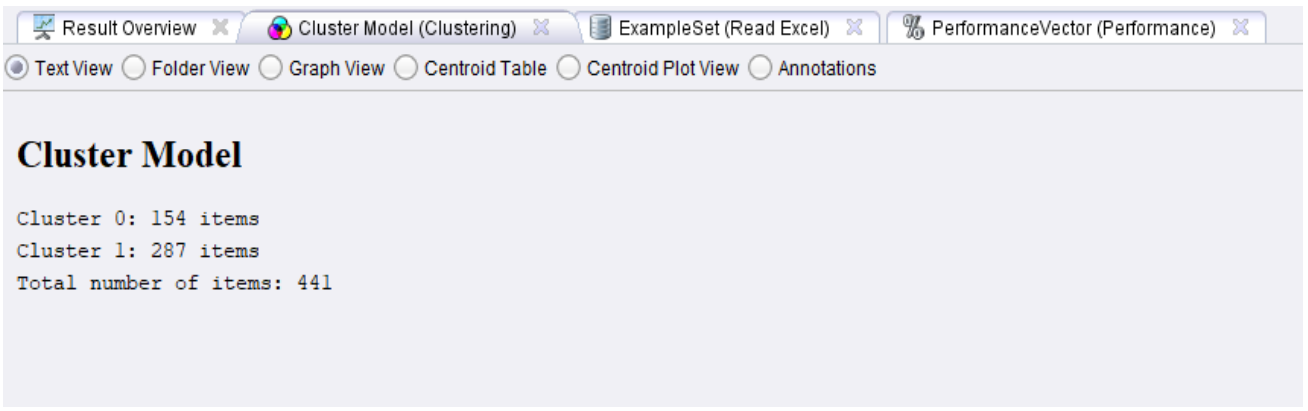

Gambar 5. Penempatan Data Ke Cluster

\begin{tabular}{|c|c|c|c|c|c|c|c|c|c|}
\hline Row No. & ID/NO & cluster & IPK & Penghasila. & Tanggunga. & .. Domisili R & RealSemester R & ... Aktivis Real & PKM \\
\hline 1 & $\mathrm{Z1}$ & cluster_1 & 3.550 & 1000000 & 2 & 2 & 6 & 0 & 0 \\
\hline 2 & $\mathrm{Z} 2$ & cluster_0 & 3.130 & 4000000 & 4 & 2 & 5 & 2 & 0 \\
\hline 3 & $\mathrm{Z3}$ & cluster_1 & 3.350 & 2000000 & 4 & 2 & 5 & 3 & 10 \\
\hline 4 & Z4 & cluster_1 & 3.400 & 1200000 & 1 & 2 & 5 & 3 & 10 \\
\hline 5 & Z5 & cluster_1 & 3.450 & 1500000 & 1 & 2 & 5 & 2 & 0 \\
\hline 6 & Z6 & cluster_1 & 3.680 & 1000000 & 4 & 2 & 5 & 0 & 0 \\
\hline 7 & 27 & cluster_1 & 3.130 & 1325000 & 4 & 2 & 6 & 3 & 10 \\
\hline 8 & Z8 & cluster_1 & 3.390 & 1500000 & 2 & 2 & 5 & 0 & 0 \\
\hline 9 & 29 & cluster_1 & 3.170 & 1800000 & 2 & 1 & 6 & 2 & 10 \\
\hline 10 & $\mathrm{Z} 10$ & cluster_0 & 3.740 & 4368000 & 3 & 2 & 5 & 2 & 10 \\
\hline 11 & Z11 & cluster_1 & 3.670 & 1500000 & 4 & 2 & 5 & 0 & 0 \\
\hline 12 & Z12 & cluster_0 & 3.130 & 3713000 & 2 & 2 & 6 & 0 & 0 \\
\hline 13 & Z13 & cluster_0 & 3.330 & 4500000 & 2 & 2 & 5 & 0 & 0 \\
\hline 14 & Z14 & cluster_0 & 3.260 & 3000000 & 2 & 2 & 6 & 0 & 0 \\
\hline 15 & Z15 & cluster_1 & 3.810 & 1650000 & 2 & 2 & 6 & 0 & 10 \\
\hline 16 & Z16 & cluster_1 & 3.330 & 2100000 & 3 & 2 & 5 & 0 & 0 \\
\hline 17 & $\mathrm{Z} 17$ & cluster_1 & 3.440 & 1500000 & 1 & 2 & 6 & 2 & 0 \\
\hline 18 & Z18 & cluster_1 & 3.530 & 1500000 & 3 & 2 & 5 & 0 & 10 \\
\hline 19 & Z19 & cluster_1 & 3.350 & 1000000 & 1 & 2 & 6 & 2 & 10 \\
\hline 20 & $\mathrm{Z} 20$ & cluster_0 & 3.440 & 3000000 & 3 & 2 & 6 & 2 & 0 \\
\hline 21 & $\mathrm{Z} 21$ & cluster_1 & 3.520 & 1061300 & 3 & 2 & 6 & 2 & 10 \\
\hline 22 & $\mathrm{Z} 22$ & cluster_0 & 3.380 & 4555400 & 3 & 2 & 5 & 0 & 0 \\
\hline 23 & $\mathrm{Z} 23$ & cluster_0 & 3.420 & 4000000 & 2 & 2 & 6 & 2 & 10 \\
\hline 24 & $Z 24$ & cluster_1 & 3.620 & 2500000 & 2 & 2 & 5 & 0 & 0 \\
\hline
\end{tabular}

Gambar 6. Rincian Cluster

Dari hasil proses cluster dihasikan 154 data pendaftar yang direkomendasikan mendapatan beasiswa sedangkan 287 data lainnya tidak mendapatkan beasiswa, dari hasil tersebut dilakukan kroscek dengan hasil penerimaan beasiswa PPA pada periode penerimaan tahun 2016 dimana data yang diterima adalah 113 dan data yang tidak mendapatkan beasiswa adalah 328 , dari proses perbandingan dengan data riil yang ada diperoleh tabel confusion matrix pada tabel 1 sebagai berikut: 
Tabel 1. Confusion Matrix

\begin{tabular}{cc}
\hline Data Aktual & \multicolumn{1}{c}{ Data Prediksi } \\
\hline True Positif $(\mathrm{TP})=113$ & False Positif $(\mathrm{FP})=41$ \\
False Negatif $(\mathrm{FN})=41$ & True Negatif $(\mathrm{TN})=287$ \\
\hline
\end{tabular}

$$
\begin{aligned}
& \text { Precision }=\frac{T P}{T P+F P}=\frac{113}{113+41}=0,73=73 \% \\
& \text { Recall }=\frac{T P}{T P+F N}=\frac{113}{113+41}=0,73=73 \% \\
& \text { Accuracy }=\frac{T P+T N}{T P+T N+F P+F N}=\frac{113+287}{113+287+41+41}=0,82=82 \%
\end{aligned}
$$

Dari penelitian yang ada di dapatkan nilai true positif 113, dimana dari 154 data prediksi yang direkomendasikan untuk diterima mencakup 113 data riil dari proses seleksi oleh biro kemahasiswaan pada periode seleksi tahun 2016. Hali ini membuktikan proses clustering dapat dilakukan untuk mempersempit data seleksi calon penerima beasiswa untuk periode yang akan datang.

\section{KESIMPULAN}

Berdasarkan penelitian yang dilakukan oleh peneliti, maka didapatkan kesimpulan bahwa metode clustering dengan algoritma $K$-Means dapat menghasilkan rekomendasi penerima beasiswa Peningkatan Prestasi Akademik (PPA) dengan melibatkan 7 atribut dan dengan jumlah dataset yang banyak. Penentuan centroid (titik pusat) sangat berpengaruh pada hasil cluster seperti pada hasil pengujian dengan data uji dan data keseluruhan menghasilkan hasil cluster yang berbeda. Pada penelitian yang dilakukan pengujian dengan seluruh data berjumlah 441 dataset, sebanyak 154 mahasiswa direkomendasikan mendapatkan beasiswa PPA sedangkan 287 lainnya tidak mendapatkan, dari 154 data hasil rekomendasi data rill pada tahun 2016 terdapat 113 data pendaftar beasiswa yang dinyatakan diterima dan telah menerima beasiswa PPA, dan setelah dilakukan proses evaluasi oleh biro kemahasiswaan beasiswa tersebut sudah dinyatakan tepat sasaran, sehingga dapat ditarik kesimpulan dengan dilakukan proses rekomendasi pendaftar beasiswa menggunakan metode cluster akan memudahkan dan mempersempit proses seleksi data dengan lebih cepat.

\section{SARAN}

Untuk meningkatkan kinerja dan penyempurnaan dari penelitian yang telah dibuat, maka dapat dibuat sebuah sistem aplikasi untuk mengimplementasikan penerimaan beasiswa PPA dengan menggunakan algoritma K-Means. Metode penelitian ini hanya berfokus pada teknik clustering dengan algoritma K-Means. Untuk penelitian selanjutnya dapat digunakan teknik dan algoritma lain. Dapat dilakukan penelitian supervised learning dengan didukung data yang lebih baik.

\section{DAFTAR PUSTAKA}

[1] J. A. D. Guterres, "Kelayakan Algoritma C45 Sebagai Pendukung Keputusan Dalam Pengajuan Penerima Beasiswa," in Seminar Nasional Teknologi Informasi , Kupang, 2015. 
[2] P. Utomo, "Analisis Kontribusi Pemberian Beasiswa Terhadap Peningkatan Prestasi Akademik Mahasiswa Fakultas Teknik Universitas Negeri Yogyakarta," JPTK, vol. XX, no. 1, pp. 68-87, Mei 2011.

[3] N. R. W, "Implementasi Algoritma K-Means Dalam Pengklasteran Mahasiswa Pelamar Beasiswa," Jurnal Ilmiah Teknologi Informasi Terapan, vol. I, no. 2, pp. 62-68, April 2015.

[4] F. Satria, "Perbandingan Kinerja Metode Ward Dan K-Means Dalam Menentukan Cluster Data Mahasiswa Pemohon Beasiswa (Studi Kasus: STMIK Pringsewu)," Jurnal TIM Darmajaya, vol. II, no. 1, pp. 12-26, Mei 2016.

[5] Jaroji, "K-Means Untuk Menentukan Calon Penerima Beasiswa Bidik Misi Di Polbeng," Jurnal Inovtek Polbeng Seri informatika, vol. I, no. 1, pp. 87-94, Juni 2016.

[6] M. Riadi, $2017 . \quad$ [Online]. Available: https://www.kajianpustaka.com/2017/09/data-mining.html.

[7] A. E. Wicaksono, "Implementasi Data Mining Dalam Pengelompokan Data Peserta Didik Di Sekolah Untuk Memprediksi Calon Penerima Beasiswa Dengan Menggunakan Algoritma K-Means (Studi Kasus SMAN 16 Bekasi)," Jurnal Teknologi Rekayasa, vol. XXI, no. 3, pp. 206-216, Desember 2016.

[8] B. Rahmat, "Implementasi K-Means Clustering Pada RapidMiner Untuk Analisis Daerah Rawan Kecelakaan," in Seminar Nasional Riset Kuantitatif Terapan 2017, Kendari, 2017. 